\title{
CS-866, a New Angiotensin II Type 1 Receptor Antagonist, Ameliorates Glomerular Anionic Site Loss and Prevents Progression of Diabetic Nephropathy in Otsuka Long-Evans Tokushima Fatty Rats
}

\author{
Kohachiro Koga, ${ }^{1}$ Sho-ichi Yamagishi, ${ }^{1}$ Masayoshi Takeuchi, ${ }^{2}$ Yosuke Inagaki, $^{1}$ Shinjiro Amano, ${ }^{1}$ \\ Tamami Okamoto, ${ }^{1}$ Tsuyoshi Saga, ${ }^{3}$ Zenji Makita, $^{4}$ and Mitsuaki Yoshizuka ${ }^{3}$ \\ ${ }^{1}$ Division of Endocrinology and Metabolism, Department of Medicine, Kurume University School \\ of Medicine, Kurume, Japan \\ ${ }^{2}$ Department of Biochemistry, Faculty of Pharmaceutical Science, Hokuriku University, Kanazawa, Japan \\ ${ }^{3}$ Department of Anatomy, Kurume University School of Medicine, Kurume, Japan \\ ${ }^{4}$ Kurume University School of Medicine, Kurume, Japan \\ Accepted July 15, 2002
}

\begin{abstract}
Background: Diabetic nephropathy is a leading cause of end-stage renal disease in industrialized countries. Previous studies have documented that angiotensin converting enzyme (ACE) inhibitors consistently reduce albuminuria and retard the progression of diabetic nephropathy. However, the involvement of angiotensin II in diabetic nephropathy is not fully understood.

Materials and Methods: In this study we compared the effects of CS-866, a new angiotensin II type 1 receptor antagonist, to that of an ACE inhibitor, temocapril hydrochloride, on the development and progression of diabetic nephropathy using Otsuka Long-Evans Tokushima fatty rats, a type II diabetes mellitus model animal.

Results: High doses of CS-866 or temocapril treatment were found to significantly improve urinary protein and $\beta_{2}$-microglobulin excretions in diabetic rats. In electron
\end{abstract}

microscopic analysis, loss of glomerular anionic sites, one of the causes of glomerular hyperpermeability in diabetic nephropathy, was found to be significantly prevented by CS-866 treatment. Light microscopic examinations revealed that both treatments ameliorated glomerular sclerosis and tubulointerstitial injury in diabetic rats. Furthermore, high doses of CS-866 or temocapril treatment significantly reduced the positive stainings for transforming growth factor- $\beta$ (TGF- $\beta$ ), vascular endothelial growth factor, and type IV collagen in glomeruli of diabetic rats. Conclusions: These results indicate that intrarenal angiotensin II type 1 receptor activation plays a dominant role in the development and progression of diabetic nephropathy. Our study suggests that CS-866 represents a valuable new drug for the treatment of diabetic patients with nephropathy.

\section{Introduction}

Diabetic nephropathy is a leading cause of end-stage renal disease and can account for disabilities and the high mortality rate in patients with this disease $(1,2)$. Although the mechanisms for the development and progression of diabetic nephropathy are not fully understood, a disturbance of the charge barrier of the glomerular basement membrane is considered to be involved in the pathogenesis of microalbuminuria in the early phase of diabetic nephropathy $(3,4)$. The loss of glomerular anionic sites are followed by mesangial expansion and tubular injury, which in concert may deteriorate renal function in diabetes.

There is a growing body of evidence that angiotensin converting enzyme (ACE) inhibition

Address correspondence and reprint requests to: Sho-ichi Yamagishi, Division of Endocrinology and Metabolism, Department of Medicine, Kurume University School of Medicine, 67 Asahi-machi, Kurume 830-0011, Japan. Phone:+81-942-31-7563; fax:+81-942-35-8943;

e-mail: shoichi@med.kurume-u.ac.jp. consistently reduces albuminuria and retards the progression of glomerulosclerosis in diabetes (5-7). However, ACE, not a specific enzyme, has a capacity to degrade bradykinin, a potent stimulator of nitric oxide and prostacyclin (8). Therefore, the main involvement of angiotensin II in the pathogenesis of diabetic nephropathy remains to be elucidated. Recently, the development of a specific angiotensin II type 1 receptor antagonist made it possible to differentiate the pathophysiologic properties of angiotensin II from that of bradykinin in diabetic nephropathy. In this study, we compared the effects of long-term administration of CS-866, a new angiotensin II type 1 receptor antagonist, to that of an ACE inhibitor, temocapril hydrochloride, on the development and progression of diabetic nephropathy using Otsuka Long-Evans Tokushima fatty (OLETF) rats, a type II diabetes mellitus model animal. The effects of these drugs on urinary protein and $\beta_{2}$-microglobulin excretions, anionic sites of glomerular basement membrane, and glomerular and tubular morphology were investigated to isolate 
the role of the blocking of the angiotensin II type 1 receptor from other factors associated with ACE inhibitor treatment.

\section{Materials and Methods Drugs}

CS-866 and temocapril hydrochloride were generously provided by Sankyo Co. Ltd (Tokyo, Japan).

\section{Animals}

Forty-six male OLETF rats, a type II diabetes mellitus model established in 1990 at the Tokushima Research Institute, were obtained from Otsuka Pharmaceutical Co. Ltd. (Tokushima, Japan). Eleven male Long-Evans Tokushima Otsuka (LETO) rats served as normal controls. The OLETF rats at aged 20 weeks were randomly divided into four groups; [1] no treatment, [2] treatment with chow containing $0.001 \%$ of CS-866 (about $0.3 \mathrm{mg} \mathrm{CS}-866 / \mathrm{d}$ ), [3] treatment with chow containing $0.01 \%$ of CS-866 (about $3 \mathrm{mg} \mathrm{CS}-866 / \mathrm{d}$ ), and [4] treatment with chow containing $0.01 \%$ of temocapril (about $3 \mathrm{mg}$ temocapril/d). Each animal was followed to 52 weeks. Rats were kept at approximately $22 \pm 3{ }^{\circ} \mathrm{C}$ and $50 \pm 20 \%$ humidity under a 12 -hr light/dark cycle. Experiments in this study were performed in accordance with Guiding Principles for the care and use of laboratory animals approved by the Japanese Pharmacological Society. The ethical committee of New Drug Development Research Center Inc. (Hokkaido, Japan) approved this study.

\section{Clinical Parameters}

Animals were placed in metabolic cages and their 24-hr urinary protein and $\beta_{2}$-microglobulin excretions were determined at 4 -week intervals. Blood samples were taken from jugular veins at 4-week intervals for the measurement of blood glucose, total cholesterol, and triglycerides. Systolic and diastolic blood pressure (BP) were monitored by the tail-cuff method (UR5000, Ueda Manufactory, Tokyo, Japan) every 8 weeks.

\section{Electron Microscopic Analysis}

At 52 weeks of age, all animals were deeply anesthetized with an injection of barbital solution, then each kidney was isolated. The renal cortex was cut into small pieces, and then immersed for $30 \mathrm{~min}$ in $0.5 \%$ polyethyleneimine (PEI) (molecular weight 1800; Wako Pure Chemical Industries Ltd., Osaka, Japan) solution, $\mathrm{pH} 7.4$, according to the method of Schuer et al. (9). After immersion, the blocks were washed with $0.1 \mathrm{mmol} / \mathrm{L}$ cacodylate-buffered solution $(\mathrm{pH} 7.4)$ and fixed with $0.1 \%$ glutaraldehyde and $2 \%$ phosphotungstic acid solution ( $\mathrm{pH} 7.4$ ). The blocks were then embedded in Qetol-812 (Nisshin EM Co., Inc., Tokyo, Japan) and ultrathin sections were examined by JEM-100SX transmission election microscopy (JEOL, Tokyo, Japan). Three glomeruli were chosen from each rat, and then three independent areas of each glomeruli were investigated. The mean numbers of PEI particles were shown per $1000 \mathrm{~nm}$ of the lamina rara externa of the glomerular basement membrane.

\section{Light Microscopic Analysis}

At 52 weeks of age, kidney tissues were fixed in carnoy's fixative and then embedded in paraffin. Tissues were stained with hematoxylin and eosin and periodic acid Schiff. Glomerular sclerosis was assessed using a semiquantitative score previously described $(10,11)$ : grade 0 , normal appearance; grade 1 , sclerotic area less than or equal to $25 \%$ of total glomerulus area; grade 2 , sclerosis of $25-50 \%$ of the area; grade 3, sclerosis of more than $50 \%$ of the area but not global; grade 4, global sclerosis. A glomerular sclerosis index was calculated by multiplying the number of glomeruli with a sclerosis score of 1 by one,

Table 1. Comparison of body weight and serum variables at week 52 and BP at week 50 in OLETF and LETO rats

\begin{tabular}{|c|c|c|c|c|c|}
\hline & \multicolumn{4}{|c|}{ OLETF rats } & \multirow[b]{2}{*}{$\begin{array}{l}\text { LETO rats } \\
\quad(n=11)\end{array}$} \\
\hline & $\begin{array}{l}\text { No treatment } \\
\quad(n=12)\end{array}$ & $\begin{array}{c}\text { CS-866 }(0.001 \%) \\
(n=11)\end{array}$ & $\begin{array}{c}\text { CS-866 }(0.01 \%) \\
(n=12)\end{array}$ & $\begin{array}{l}\text { Temocapril } \\
(n=11)\end{array}$ & \\
\hline Body weight (g) & $748.6 \pm 33.0$ & $865.6 \pm 15.3^{\# \#}$ & $792.3 \pm 10.5$ & $766.7 \pm 13.9$ & $546.8 \pm 6.5^{* *}$ \\
\hline Blood glucose (mmol/L) & $10.35 \pm 0.38$ & $10.53 \pm 0.54$ & $10.49 \pm 0.38$ & $10.16 \pm 0.41$ & $7.54 \pm 0.15^{* *}$ \\
\hline Systolic BP (mmHg) & $153.4 \pm 4.3$ & $138.9 \pm 5.0^{\#}$ & $132.1 \pm 3.3^{\# \#}$ & $124.0 \pm 3.2^{\# \#}$ & $128.5 \pm 4.7^{* *}$ \\
\hline Diastolic BP (mmHg) & $117.3 \pm 4.9$ & $112.6 \pm 4.7$ & $100.8 \pm 2.1^{\# \#}$ & $100.1 \pm 3.3^{\# \#}$ & $98.2 \pm 3.4^{* *}$ \\
\hline Cholesterol (mmol/L) & $4.37 \pm 0.23$ & $3.97 \pm 0.20$ & $2.42 \pm 0.13^{\# \#}$ & $2.03 \pm 0.07^{\# \#}$ & $1.76 \pm 0.04^{* *}$ \\
\hline Triglyceride (mmol/L) & $2.63 \pm 0.37$ & $2.80 \pm 0.27$ & $1.26 \pm 0.14^{\#}$ & $0.96 \pm 0.08^{\# \#}$ & $0.28 \pm 0.03 * *$ \\
\hline
\end{tabular}

${ }^{* *} p<0.01$ compared with nontreated OLETF rats (F- $t$ test).

${ }^{\#} p<0.05,{ }^{\# \#} p<0.01$, compared with nontreated OLETF rats (Dunnett's $t$-test). 


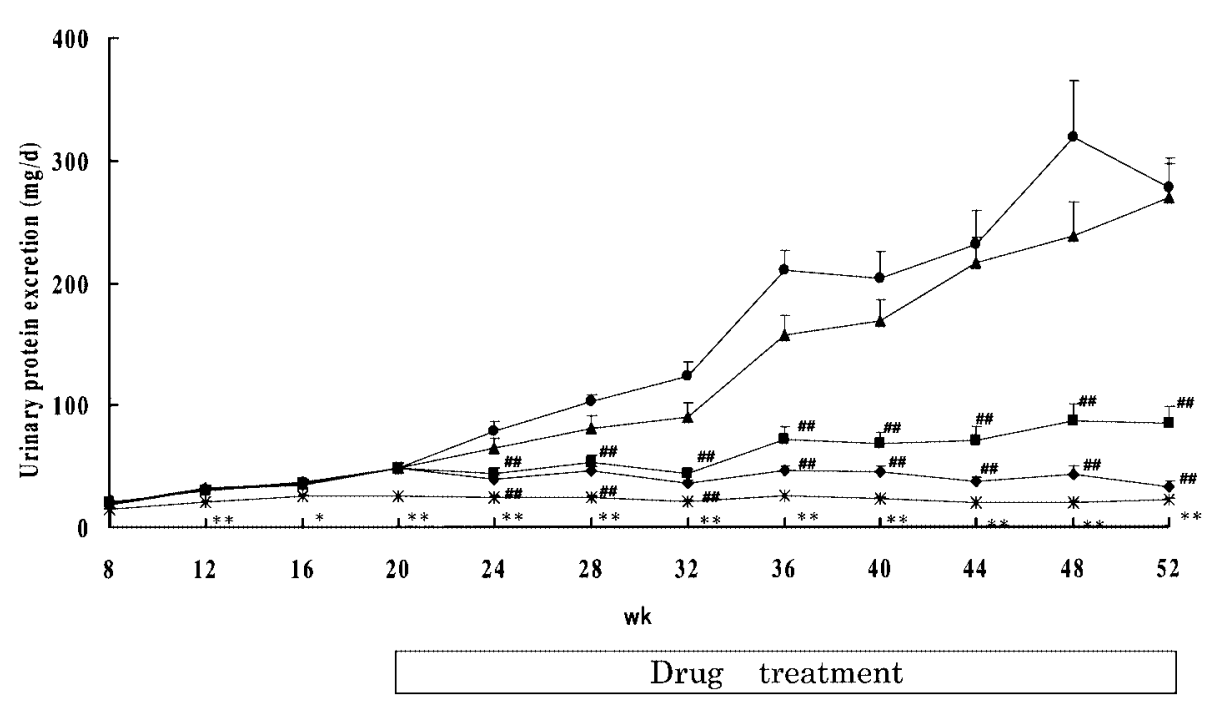

Fig. 1. Effects CS-866 or temocapril treatment on urinary protein excretions in OLETF rats. High doses of CS-866 or temocapril significantly reduced the elevation of urinary protein excretion in OLETF rats. Nontreated OLETF rats $(\bullet) ; 0.001 \%$ CS-866-treated OLETF rats $(\mathbf{\Lambda}) ; 0.01 \%$ CS-866-treated OLETF rats $(\boldsymbol{\square})$; temocapril-treated OLETF rats $(\bullet)$; LETO rats $(*) .{ }^{*} p<$ 0.05. ${ }^{* *} p<0.01$ compared with nontreated OLETF rats (F- $t$ test). ${ }^{\# \#} p<0.01$ compared with nontreated OLETF rats (Dunnett's $t$-test).
2 by two, 3 by three, and 4 by four (12). These values were summed and divided by the number of glomeruli assessed. The index of tubular atrophy was assessed using a semiquantitative score: grade 0 , normal appearance; grade 1 , atrophic area less than or equal to $12.5 \%$ of total tubules; grade 2 , atrophy of $12.5-25 \%$ of the total tubules; grade 3, atrophy of $25-50 \%$ of the total tubules; grade 4 , atrophy of more than $50 \%$ of the total tubules. The index of tubular atrophy was calculated by the same method as that of glomerular sclerosis.

\section{Immunohistochemistry}

Immunohistochemical staining was performed as described previously (13). Briefly, for transforming growth factor- $\beta$ (TGF- $\beta$ ) and vascular endothelial growth factor (VEGF) immunohistochemical staining, 50 glomeruli were randomly chosen and the number positively stained was counted. Immunohistochemical staining for type IV collagen was semiquantitative by using a scale of $0-2(0=$ no staining, $2=$ maximum staining) as described previously (13) and the average score of 100 randomly selected glomeruli was calculated. Negative control staining without antibodies yielded no positive signals in our immunohistochemical analysis. All the histologic examinations were done by observers who were masked to the study groups of origin.

\section{Statistical Analysis}

The F- $t$ test and Dunnett's $t$-test were used for statistical analysis. Values are expressed as mean \pm SEM. $p$ values of $<0.05$ were considered statistically significant.

\section{Results}

Clinical Characteristics of Animals

Table 1 shows the clinical characteristics of the 46 OLETF rats and 11 LETO rats. OLETF rats were subdivided into four groups according to the type of treatment. OLETF rats had higher body weights and food consumption than LETO rats and their blood glucose levels were moderately elevated at 12 weeks,

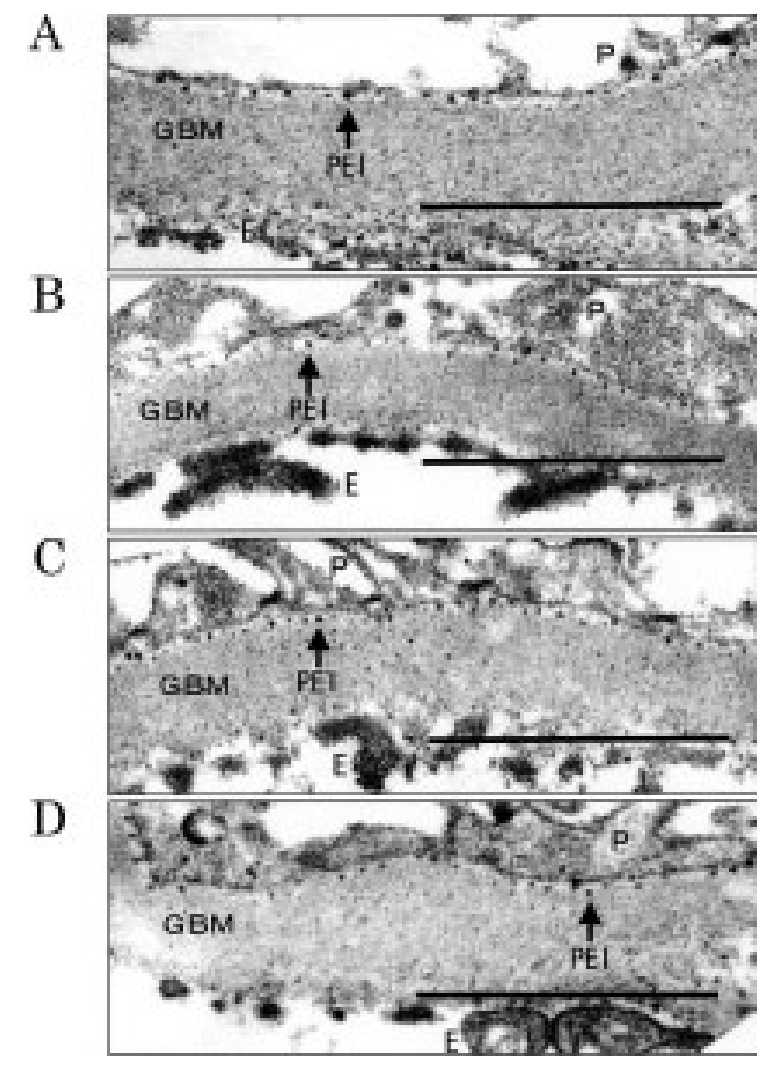

Fig. 2. Electron microscopic photographs of glomeruli. Anionic sites in the glomerular basement membrane of OLETF rats (A) No treatment.(B) Low-dose $(0.001 \%)$ CS-866 treatment. (C) High-dose $(0.01 \%)$ CS-866 treatment. (D) Temocapril treatment. P, podocyte; E, endothelium; GBM, glomerular basement membrane. Bar, $1000 \mathrm{~nm}$. 
Table 2. Effects of CS-866 or temocapril on anionic site loss in glomerular basement membrane

\begin{tabular}{|c|c|c|c|c|c|}
\hline & \multicolumn{4}{|c|}{ OLETF rats } & \multirow[b]{2}{*}{$\begin{array}{l}\text { LETO rats } \\
(n=11)\end{array}$} \\
\hline & $\begin{array}{l}\text { No treatment } \\
\quad(n=12)\end{array}$ & $\begin{array}{c}\text { CS-866 }(0.001 \%) \\
(n=11)\end{array}$ & $\begin{array}{c}\text { CS-866 }(0.01 \%) \\
(n=12)\end{array}$ & $\begin{array}{l}\text { Temocapril } \\
(n=11)\end{array}$ & \\
\hline Anionic sites & $8.8 \pm 0.7$ & $9.0 \pm 0.6$ & $12.6 \pm 0.8^{\# \#}$ & $10.6 \pm 0.4$ & $12.4 \pm 0.7^{* *}$ \\
\hline \multicolumn{6}{|c|}{ 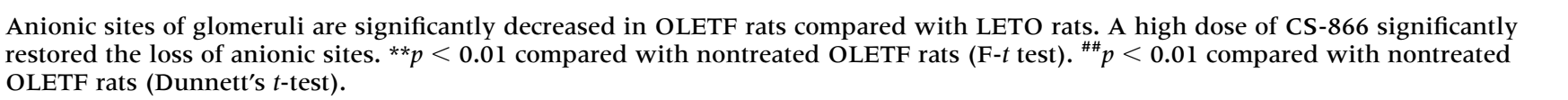 } \\
\hline
\end{tabular}

increased with time, and remained elevated until the end of the experiment. CS-866 or temocapril treatment did not affect the levels of blood glucose, food consumption, or water intake. However, body weight in low-dose CS-866 groups are significantly higher than that in OLETF rats. Systolic and diastolic BP were significantly higher in OLETF rats. High-dose CS-866 $(0.01 \%)$ and temocapril treatments were equally potent in reducing systolic and diastolic BP during the experiments. Serum levels of total cholesterol and triglyceride in OLETF rats gradually increased from 36 weeks, but the elevations were significantly prevented by a high dose of CS866 or temocapril.

\section{Effects on Proteinuria}

As shown in Figure 1, urinary protein excretion levels in OLETF rats were not different from those of LETO rats until 12 weeks. However, proteinuria markedly increased from 20 weeks in OLETF rats and remained elevated until the end of the experiment. A high dose of CS-866 or temocapril significantly reduced the increase in urinary protein excretions in OLETF rats. The proteinuria-reducing effect
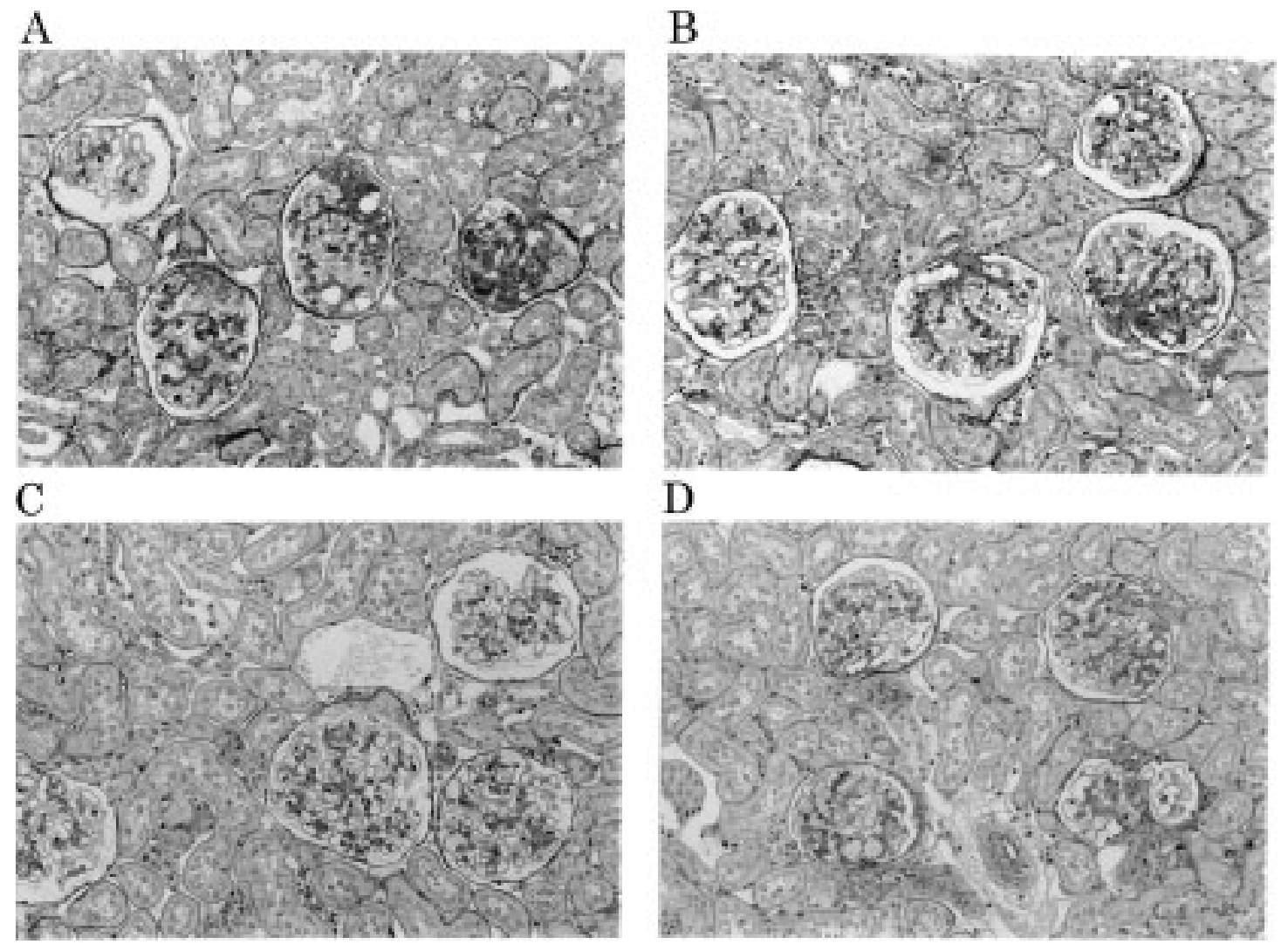

D

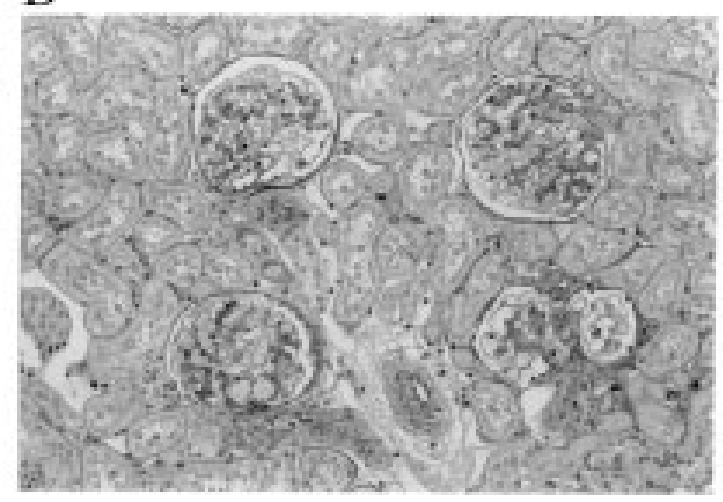

Fig. 3. Periodic acid-Schiff staining of glomeruli in OLETF rats. (A) No treatment. (B) Low-dose (0.001\%) CS-866 treatment. (C) High-dose $(0.01 \%)$ CS-866 treatment. (D) Temocapril treatment. 
Table 3. Glomerular sclerosis index in OLETF rats

\begin{tabular}{ccccc}
\hline & $\begin{array}{c}\text { No treatment } \\
(n=12)\end{array}$ & $\begin{array}{c}\text { CS-866 }(0.001 \%) \\
(n=11)\end{array}$ & $\begin{array}{c}\text { CS-866 (0.01\%) } \\
(n=12)\end{array}$ & $\begin{array}{c}\text { Temocapril } \\
(n=11)\end{array}$ \\
\hline Sclerosis index & $1.82 \pm 0.05$ & $1.73 \pm 0.03$ & $1.17 \pm 0.05^{\# \#}$ & $1.47 \pm 0.05^{\# \#}$ \\
\hline
\end{tabular}

High doses of CS-866 or temocapril significantly decreased the glomerular sclerosis index in OLETF rats.

${ }^{\# \#} p<0.01$ (Dunnett's $t$-test).
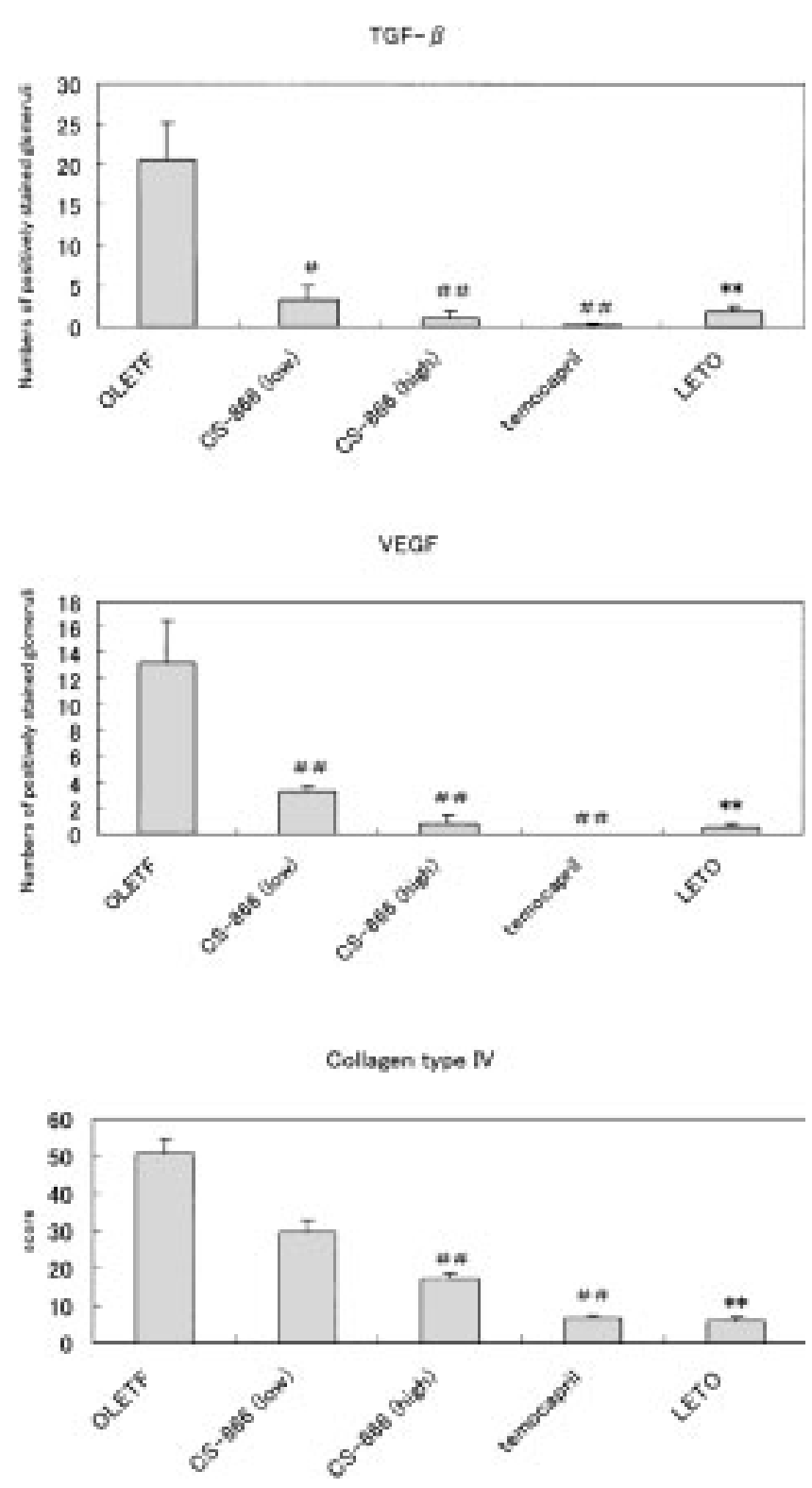

Fig. 4. Quantitative representation of immunostainings for TGF- $\boldsymbol{\beta}$, VEGF, and collagen type IV in glomeruli. ${ }^{* *} p<0.01$ compared with nontreated OLETF rats (F-t test). ${ }^{\#} p<0.05$ and ${ }^{\# \# p}<0.01$ compared with nontreated OLETF rats (Dunnett's $t$-test). of temocapril was a little greater than that of a high dose of CS-866; however, there were no significant differences in the extent of proteinuria between the two groups during the experiment.

\section{Effects on Anionic Sites}

Loss of anionic sites on glomerular basement membrane is initially responsible for the development of albuminuria in early phase of diabetic nephropathy $(3,4)$. Therefore, we next investigated whether these treatments could restore the decrease of the charge barrier of glomeruli in OLETF rats. As shown in Figure 2 and Table 2, a decrease in numbers of anionic sites in the glomerular basement membrane in OLETF rats was significantly prevented by a high dose of CS-866.

\section{Effects on Glomerular Morphology}

As shown in Figure 3, a high dose of CS-866 or temocapril significantly improved glomerulosclerosis in OLETF rats. Although both treatments improved the index of sclerosis of glomeruli, the protective effect of a high dose of CS-866 was significantly higher than that of temocapril (Table 3).

\section{Effects on Immunohistochemical Staining}

As shown in Figures 4 and 5, increased TGF- $\beta$, VEGF and collagen type IV stainings were observed in the glomeruli of OLETF rats compared with LETO rats. High-dose CS-866 or temocapril was found to significantly reduce the positive stainings for TGF- $\beta$, VEGF, and collagen type IV in OLETF rats.

\section{Effects on Tubular Function and Morphology}

Urinary $\beta_{2}$-microglobulin excretion levels are known to be one of the representative markers for tubular injury in diabetes (14); therefore we studied whether tubular injury was ameliorated by either CS-866 or temocapril treatment. As shown in Figure 6, urinary $\beta_{2}$-microglobulin excretions in nontreated OLETF rats dramatically increased from 20 weeks and remained higher compared with those of LETO rats during the experiment. High-dose CS-866 or temocapril treatment was found to significantly decrease urinary $\beta_{2}$-microglobulin excretions in OLETF rats (Fig. 6). Both these treatments also 
improved the index of tubular atrophy in OLETF rats (Table 4).

\section{Discussion}

We found in the present study that CS-866, a new angiotensin II type 1 receptor antagonist, prevented the elevation of urinary protein excretions in a dosedependent manner in OLETF rats. Because equihypotensive doses of CS-866 (high dose) and temocapril equally ameliorated the elevation of proteinuria (Table 1, Fig. 1), angiotensin II type 1 receptor interaction may be mainly involved in the development of proteinuria in diabetic nephropathy. Recently, Ravid et al. (15) demonstrated that use of an ACE inhibitor reduced the extent of proteinuria and slowed the decline of renal function in normotensive type II diabetic patients with normoalbuminuria over a 6-year follow-up period. These observations suggest that intrarenal angiotensin II type 1 receptor activation may initially participate in the development and progression of diabetic nephropathy. Recently, Taniguchi et al. (16) showed that amlodipine failed to improve nephropathy of OLETF rats despite lowering of blood pressure. These studies support the concept that renoprotective effects of CS-866 and temocapril would be related to specific actions on the renin-angiotensin system rather than to undifferentiated lowering of blood pressure.

Microalbuminuria in the early phase of diabetic nephropathy is considered to be caused initially by a disturbance of the charge barrier of the glomerular basement membrane, in other words, the loss of anionic sites in glomeruli $(3,4)$. Heparan sulfate proteoglycan, a major component of anionic sites in the glomerular basement membrane, is depolymeralized and degraded by reactive oxygen species (ROS) $(17,18)$. Because hyperglycemia-induced angiotensin II type 1 receptor activation is found to be a predominant source of ROS in mesangial cells $(19,20)$, CS-866 may improve proteinuria through preservation of anionic sites in glomeruli by decreasing ROS generation. In support of this, angiotensin II was shown to decrease the production of heparan sulfate proteoglycan by mesangial cells through interaction with type 1 receptor (21). Hyperglycemia itself is also reported to suppress the mesangial synthesis and secretion of heparan sulfate proteoglycan $(22,23)$. This may be one reason that CS-866 treatment did not completely inhibit the elevation of proteinuria in OLETF rats. In our present study, temocapril treatment does not improve anionic site loss significantly, although the level of proteinuria in the group of temocapril is significantly decreased compared to that in the untreated group. These results suggest that temocapril treatment could improve proteinuria in OLETF rats through other mechanism, such as degradation of bradykinin.

The present study further showed that CS-866 prevented the progression of glomerulosclerosis in OLETF rats. Along with others we have recently
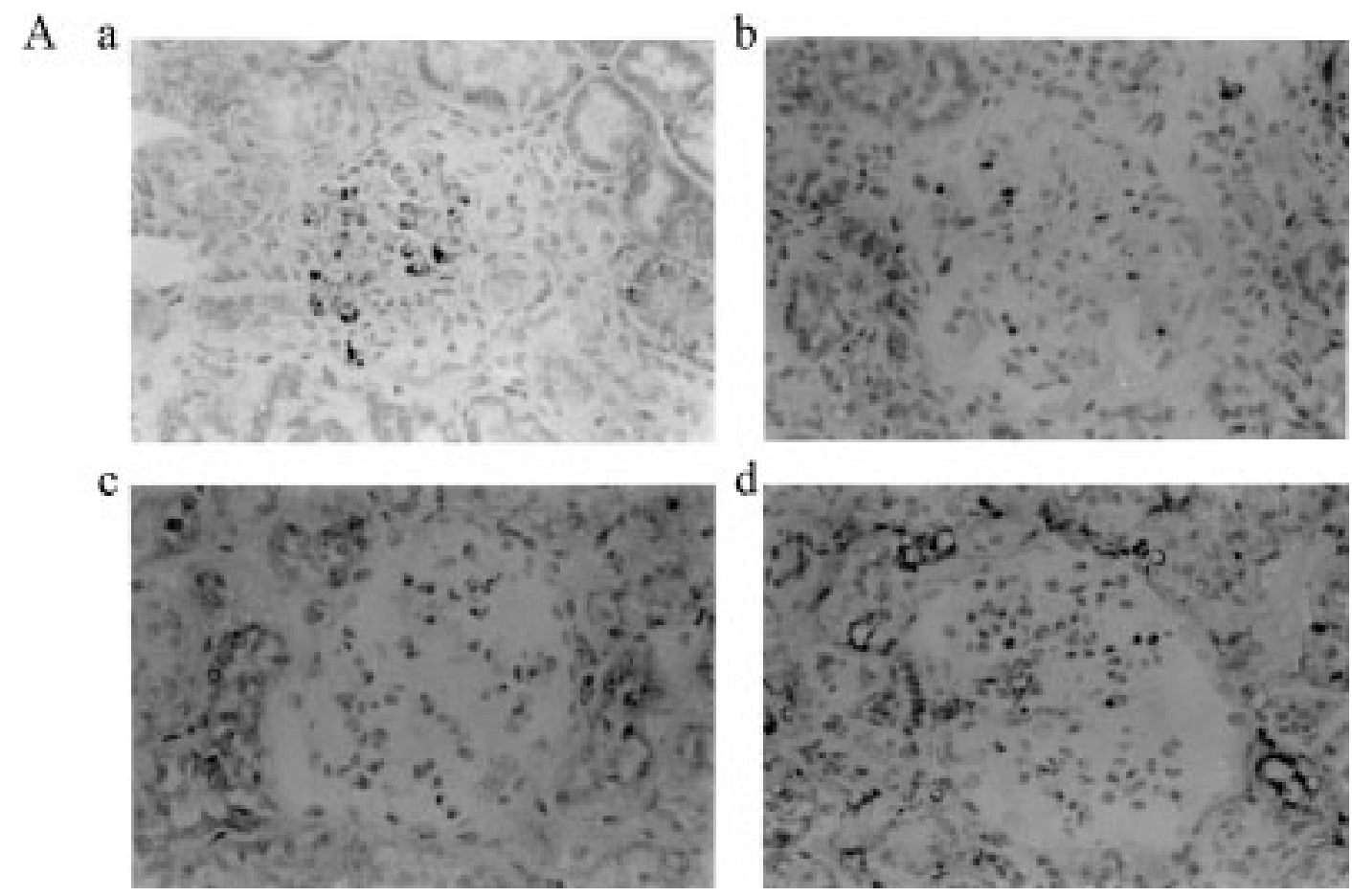

Fig. 5. Typical photomicrographs of immunostainings for TGF- $\beta$ (A), VEGF (B), and collagen type IV (C) in glomeruli. (a) No treatment. (b) Low-dose $(0.001 \%)$ CS-866 treatment. (c) High-dose $(0.01 \%)$ CS-866 treatment. (d) Temocapril treatment. 

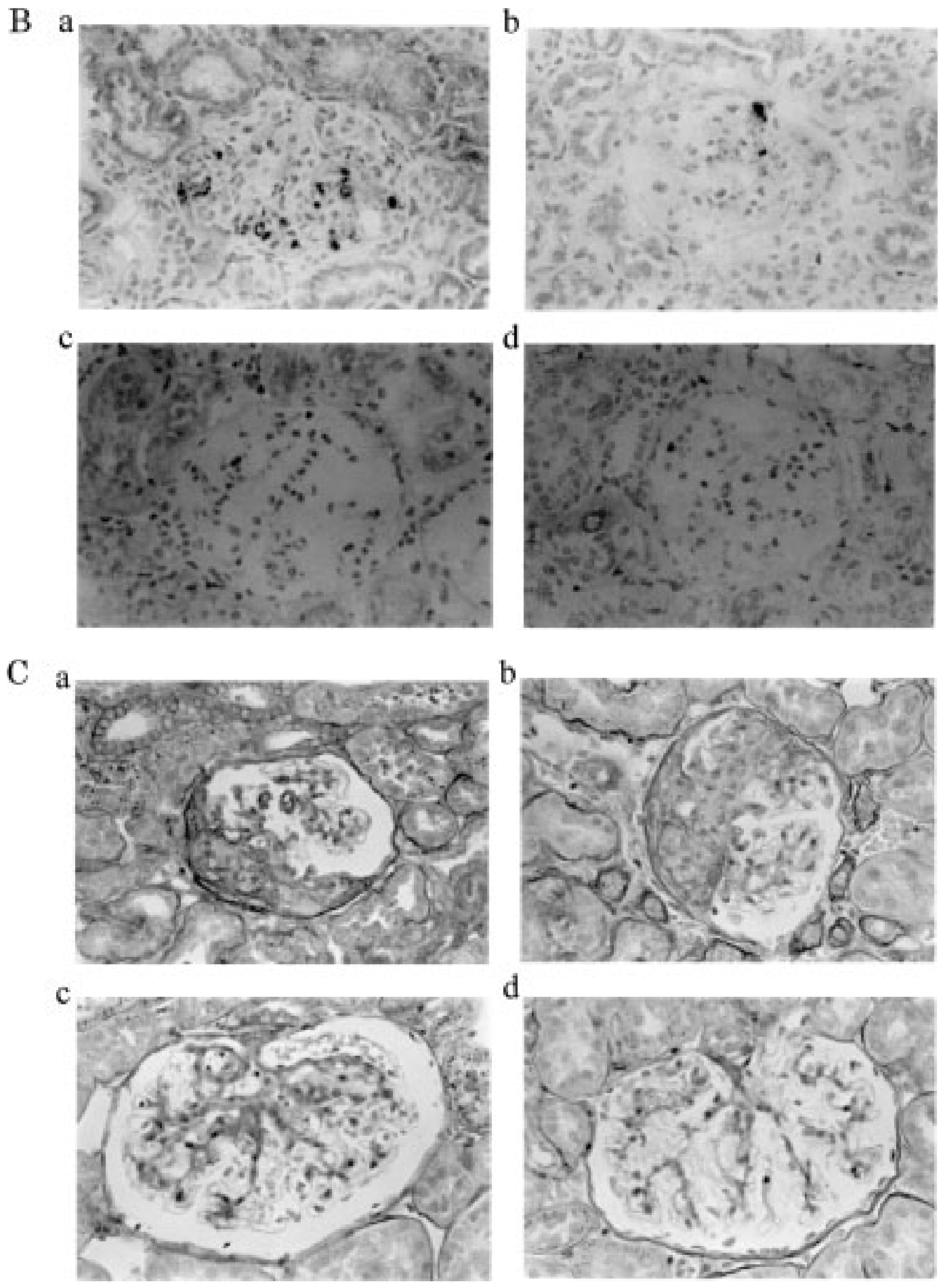

Fig. 5. (Continued)

shown that overproduction of VEGF and TGF- $\beta$ elicited the functional and structural changes of diabetic nephropathy $(13,24,25)$. In fact, both treatments retarded the progression of glomerulosclerosis by blocking overproduction of these growth factors in glomeruli. The observation that angiotensin II enhances the production of VEGF and
TGF- $\beta$ by mesangial cells further suggests the involvement of angiotensin II type 1 receptor interaction in overproduction of VEGF and TGF- $\beta$ in diabetic nephropathy $(26,27)$. In our study, lowdose CS-866 failed to improve nephropathy in OLETF rats despite reduction of positive stainings for TGF- $\beta$ and VEGF. These results suggest that the 


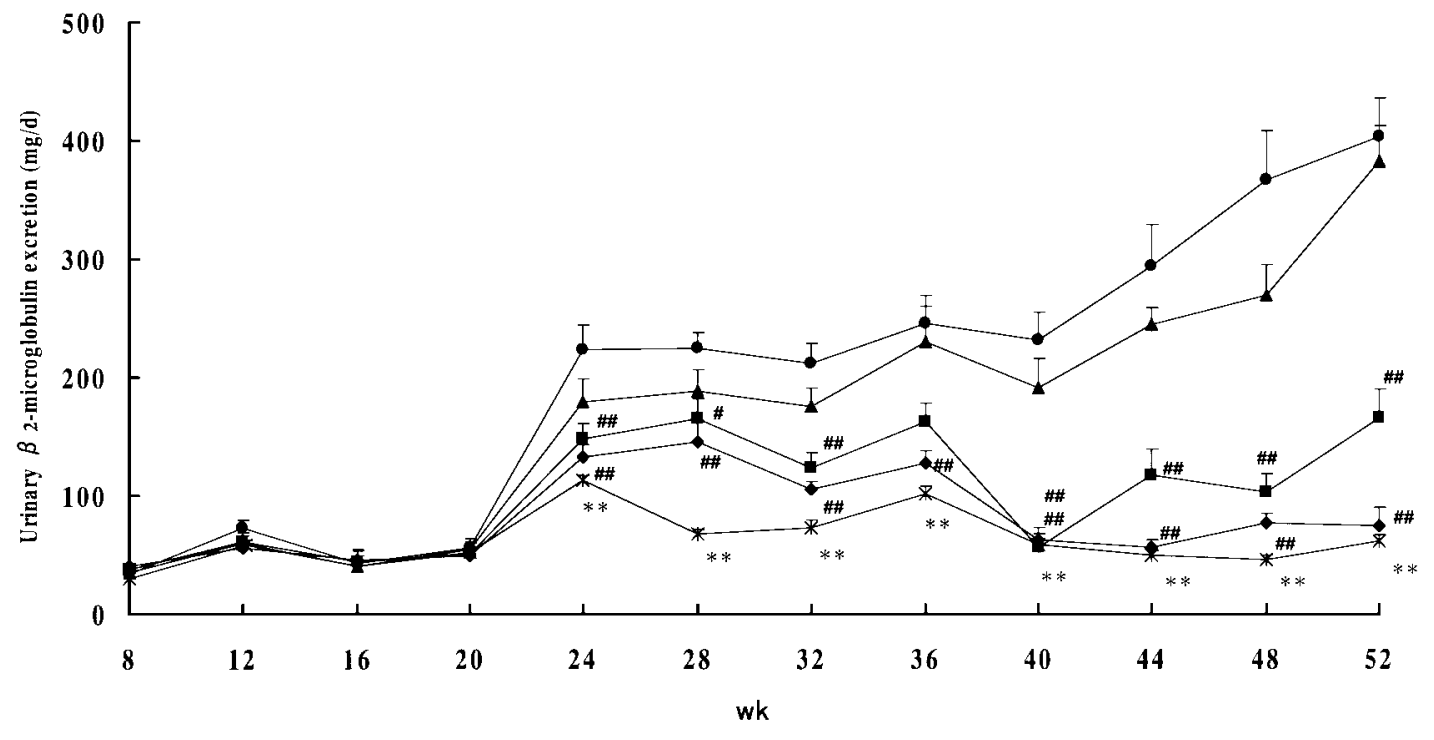

Drug treatment

Fig. 6. Effects CS-866 or temocapril treatment on urinary $\boldsymbol{\beta}_{\mathbf{2}}$-microglobulin excretions in OLETF rats. (๑) Nontreated OLETF rats; $(\Delta) 0.001 \%$ CS-866-treated OLETF rats; $(\boldsymbol{\square})$ 0.01\% CS-866-treated OLETF rats; $(\diamond)$ temocapril-treated OLETF rats; $\left({ }^{*}\right)$ LETO rats. ${ }^{* *} p<0.01$ compared with nontreated OLETF rats (F- $t$ test). ${ }^{\#} p<0.05$ and ${ }^{\# \#} p<0.01$ compared with nontreated OLETF rats (Dunnett's $t$-test).

concomitant lowering of total cholesterol and triglyceride levels might also be involved in renoprotective effects of CS-866 or temocapril. Many experimental studies have demonstrated a significant deleterious role for hyperlipidemia in both the initiation and progression of renal injuries, supporting our speculation (28).

We showed here that high-dose CS-866 or temocapril significantly lowered both cholesterol and triglyceride levels in OLETF rats. Because CS-866 or temocapril were reported to have no effect on plasma lipid levels in type II diabetic animals or patients $(29,30)$, the effects of CS-866 or temocapril on lipid parameters in OLETF rats might be speciesspecific actions.

In this study, the renoprotective effects of highdose CS-866 on glomerular sclerosis was significantly larger than that of an equihypotensive dose of temocapril. Angiotensin II type 1 receptor antagonists result in the unopposed stimulation of angiotensin II type 2 receptor, which may explain the more beneficial effects of CS-866 on the progression of glomerular sclerosis $(31,32)$.

High-dose CS-866 or temocapril treatment was also found to improve tubular injury in OLETF rats. Tubular atrophy and interstitial fibrosis most closely correlated with declining creatinine clearance, one of the representative prognostic markers for diabetic nephropathy (33). Our present study suggests that the new angiotensin II type 1 receptor antagonist, CS-866, may prove useful as a therapeutic strategy for the treatment of diabetic patients with nephropathy.

\section{Acknowledgments}

We thank Mr. Katsuharu Iwadate and Mr. Noriyuki Yamazaki for their helpful comments during the

Table 4. Index of tubular atrophy in OLETF rats

\begin{tabular}{lccc}
\hline & $\begin{array}{c}\text { No treatment } \\
(n=12)\end{array}$ & $\begin{array}{c}\text { CS-866 (0.001\%) } \\
(n=11)\end{array}$ & $\begin{array}{c}\text { CS-866 (0.01\%) } \\
(n=12)\end{array}$ \\
\hline Index of tubular atrophy & $3.0 \pm 0.2$ & $3.0 \pm 0.2$ & $\begin{array}{c}\text { Temocapril } \\
(n=11)\end{array}$ \\
\hline
\end{tabular}

High-dose CS-866 or temocapril treatment significantly improved the tubular atrophy index in OLETF rats. ${ }^{\#} p<0.05$ and ${ }^{\# \#} p<0.01$ compared with OLETF rats (Dunnett's $t$-test). 
preparation of this manuscript. This study was supported in part by Grants of Venture Research and Development Centers from the Ministry of Education, Culture, Sports, Science, and Technology, the Suzuken Memorial Foundation, and the Mochida Memorial Foundation for Medical and Pharmaceutical Research, Japan.

\section{References}

1. Yamagishi S, Fujimori H, Yonekura H, Yamamoto Y, Yamamoto H. (1998) Advanced glycation endproducts inhibit prostacyclin production and induce plasminogen activator inhibitor-1 in human microvascular endothelial cells. Diabetologia 41: 1435-1441.

2. Friedman EA. (1990) Diabetic renal disease. In: Lifkin $\mathrm{H}$, Porte D (ed). Ellenberg and Rifkin's Diabetes Mellitus, Theory and Practice. New York: Elsevier; 684-709.

3. Moriya T, Nakazawa K, Itoh N, et al. (1993) Loss of glomerular anionic sites and the development of albuminuria in rats with streptozotocin-induced diabetes. Nephron 65: 444-448.

4. Van den Born J, van Kraats AA, Bakker MAH, et al. (1995) Reduction of heparan sulphate-associated anionic sites in the glomerular basement membrane of rats with streptozotocin-induced diabetic nephropathy. Diabetologia 38: 1169-1175.

5. Hommel E, Parving HH, Mathiesen E, Edsberg B, Nielsen MD, Giese J. (1986) Effects of captopril on kidney function in insulin-dependent diabetic patients with nephropathy. BMJ 293: 467-470.

6. Lewis EJ, Hunsicker LG, Bain RP, Rohde RD. (1993) The effect of angiotensin-converting enzyme inhibition on diabetic nephropathy. The Collaborative Study Group. N. Engl. J. Med. 329: 1456-1462.

7. Heart Outcomes Prevention Evaluation (HOPE) Study Investigators. (2000) Effects of ramipril on cardiovascular and microvascular outcomes in people with diabetes mellitus: results of the HOPE study and MICRO-HOPE substudy. Lancet 355: 253-259.

8. Vanhoutte PM. (1989) Endothelium and control of vascular function. State of the art lecture. Hypertension 13: 658-667.

9. Schuer JW, Kalicharan D, Hoedemaeker PHJ, Molenaar I. (1978) The use of polyethyleneimine for demonstration of anionic sites in basement membranes and collagen fibrils. J. Histochem. Cytochem. 26: 688-689.

10. Raij L, Azar S, Keane W. (1984) Mesangial immune injury, hypertension, and progressive glomerular damage in Dahl rats. Kidney Int. 26: 137-143.

11. Saito T, Sumithraun E, Glasgow EF, Atkins RC. (1987) The enhancement of aminonucleoside nephrosis by the co-administration of protamin. Kidney Int. 32: 691-699.

12. Nakamura T, Obata J, Kimura H, et al. (1999) Blocking angiotensin II ameliorates proteinuria and glomerular lesions in progressive mesangioproliferative glomerulonephritis. Kidney Int. 55: 877-889.

13. Tsuchida K, Makita Z, Yamagishi S, et al. (1999) Suppression of transforming growth factor beta and vascular endothelial growth factor in diabetic nephropathy in rats by a novel advanced glycation end product inhibitor, OPB-9195. Diabetologia 42: 579-588.

14. Gilbert RE, Cooper ME. (1999) The tubulointerstitium in progressive diabetic kidney disease: more than an aftermath of glomerular injury? Kidney Int. 56: 1627-1637.
15. Ravid M, Brosh D, Levi Z, Dayan YB, Ravid D, Rachmani R. (1998) Use of enalapril to attenuate decline in renal function in normotensive, normoalbuminuric patients with type 2 diabetes mellitus. Ann. Intern. Med. 128: 982-988.

16. Taniguchi M, Kim S, Zhan Y, Iwao H. (2002) Role of intrarenal angiotensin-converting enzyme in nephropathy of type II diabetic rats. Hypertens. Res. 25: 287-294.

17. Metcalfe DD, Thompson HL, Klebanoff SJ, Henderson WR Jr. (1990) Oxidative degradation of rat mast-cell heparin proteoglycan. Biochem. J. 272: 51-57.

18. Raats CJI, Born JVD, Berden JHM. (2000) Glomerular heparan sulfate alterations: Mechanisms and relevance for proteinuria. Kidney Int. 57: 385-400.

19. Jaimes EA, Galceran JM, Raij L. (1998) Angiotensin II induces superoxide anion production by mesangial cells. Kidney Int. 54: 775-784.

20. Dzau VJ.(2001) Tissue angiotensin and pathobiology of vascular disease. A unifying hypothesis. Hypertension 37: 1047-1052.

21. Van Det NF, Tamsma JT, van den Born J, et al. (1996) Differential effects of angiotensin II and transforming growth factor beta on the production of heparan sulfate proteoglycan by mesangial cells in vitro. J. Am. Soc. Nephrol. 7: 1015-1023.

22. Yaoita E, Oguri K, Okayama E, et al. (1990) Isolation and characterization of proteoglycans synthesized by cultured mesangial cells. J. Biol. Chem. 265: 522-531.

23. Silbiger S, Schlondorff D, Crowley S, et al. (1993) The effect of glucose on proteoglycans produced by cultured mesangial cells. Diabetes 42: 1815-1822.

24. Vriese ANSD, Tilton RG, Elger M, Stephan CC, Kriz W, Lameire NH. (2001) Antibodies against vascular endothelial growth factor improve early renal dysfunction in experimental diabetes. J. Am. Soc. Nephrol. 12: 993-1000.

25. Sharma K, Ziyadeh FN. (1995) Hyperglycemia and diabetic kidney disease: the case for transforming growth factor- $\beta$ as a key mediator. Diabetes 44: 1139-1146.

26. Pupilli C, Lasagni L, Romagnani P, et al. (1999) Angiotensin II stimulates the synthesis and secretion of vascular permeability factor/vascular endothelial growth factor in human mesangial cells. J. Am. Soc. Nephrol. 10: 245-255.

27. Kagami S, Border WA, Miller DE, Noble NA. (1994) Angiotensin II stimulates extracellular matrix protein synthesis through induction of transforming growth factor- $\beta$ expression in rat glomerular mesangial cells. J. Clin. Invest. 93: 2431-2437.

28. Bonnet F, Cooper ME. (2000) Potential influence of lipids in diabetic nephropathy: insights from experimental data and clinical studies. Diabetes Metab. 26: 254-264.

29. Koike H. (2001) New pharmacological aspects of CS-866, the newest angiotensin II receptor antagonist. Am. J. Cardiol. 87: 33C-36C.

30. Miyashita Y, Ito Y, Hasiguchi S, et al. (2001) Effect of temocapril hydrochloride on serum lipid levels in patients with hypertensive type 2 diabetes mellitus. J. Atheroscler. Thromb. 8: $25-29$.

31. Ichiki T, Labosky PA, Shiota C, et al. (1995) Effects on blood pressure and exploratory behaviour of mice lacking angiotensin II type-2 receptor. Nature 377: 748-750.

32. Morrissey JJ, Klahr S. (1999) Effects of AT2 receptor blockade on the pathogenesis of renal fibrosis. Am. J. Physiol. 276: F39-45.

33. Taft JL, Nolan CJ, Yeung SP, Hewitson TD, Martin FIR. (1994) Clinical and histological correlations of decline in renal function in diabetic patients with proteinuria. Diabetes 43: 1046-1051. 